ORN $-P-1601$
CONA $-650918-5$

Conf- $650918-5$

\title{
STABILITY OF AROMATIC DILUENTS AND SOLVENT EXTRACTION REAGENTS IN RADIOCHEMICAL PROCESSING*
}

Charles A. Blake, Jr. and J. M. Schmitt

Oak Ridge National Laboratory

Dak Ridge, Tennessee

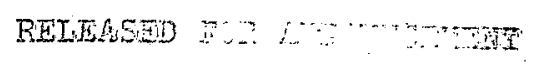

IN NUOUE?

To be presented at the

INTERNATIONAL CONFERENCE ON THE CHEMISTRY OF THE SOLVENT EXTRACTION OF METALS

on September 27-29, 1965; Harwe11, England

To be published after editorial review

in the Proceedings of the Conference

\footnotetext{
* Research sponsored by the U. S. Atomic Energy Commission under contract with the Union Carbide Corporation
} 


\section{DISCLAIMER}

This report was prepared as an account of work sponsored by an agency of the United States Government. Neither the United States Government nor any agency Thereof, nor any of their employees, makes any warranty, express or implied, or assumes any legal liability or responsibility for the accuracy, completeness, or usefulness of any information, apparatus, product, or process disclosed, or represents that its use would not infringe privately owned rights. Reference herein to any specific commercial product, process, or service by trade name, trademark, manufacturer, or otherwise does not necessarily constitute or imply its endorsement, recommendation, or favoring by the United States Government or any agency thereof. The views and opinions of authors expressed herein do not necessarily state or reflect those of the United States Government or any agency thereof. 


\section{DISCLAIMER}

Portions of this document may be illegible in electronic image products. Images are produced from the best available original document. 


\section{DISCLAIMER}

The enclosed document has not received any secondary reviews by the U.S. Department of Energy's Office of Scientific and Technical Information (OSTI) for public releasability Post 9/11. It is being made available with the understanding that any further distribution, beyond the requesting organization, is the responsibility of the receiving organization/individual. Any distribution outside the DOE community may require additional reviews by the originating site in compliance with Secretary Abraham's May 30, 2002, memorandum titled "Safeguarding Information Pertaining to Weapons of Mass Destruction and Other Sensitive Information." 


\section{STABILITY OF AROMATIC DILUENTS AND SOLVENT EXTRACTION REAGENTS IN RADIOCHEMICAL PROCESSING ${ }^{*}$}

Charles A. Blake, Jr. and J. M. Schmitt

Oak Ridge National Laboratory

Oak Ridge, Tennessee

\section{ABSTRACT}

The stabilities of some commercial aromatic diluents, especially the mixed isomers of diethylbenzene, DEB, are determined and examined with respect to their effect on the use of the diluents in solvent extraction processes. Degradation was by mixing the organic phase with an acidic aqueous phase, usually $2 \mathrm{M} \mathrm{HNO}_{3}$, in the presence or absence of ${ }^{60}$ Co gamma radiation. The degraded solvent was examined by severa 1 techniques; measurement of extraction ability, gas liquid and column chromatography, distillation, infra red and nuclear magnetic resonance spectrometry, differential thermal analysis, and elemental analysis. Exposure of $1 \mathrm{M}$ TBP/DEB solution while stirring with $2 \mathrm{M} \mathrm{HNO}_{3}$ to 2 watt $\mathrm{hr} / 1$ radiation degraded about $0.3 \%$ of the $\mathrm{DEB}$. At $70^{-}$watt $\mathrm{hr} / 1$ about $10 \%$ of the DEB degraded. The meta isomer was the most stable. The principle DEB products were ethylacetophenones and 1-nitroethyl-ethy1benzenes and are poor extractants for uranium and fission products. Impurities frequently associated with DEB degraded to compounds which extracted fission products strongly. DEB degraded 2 to 5 times faster when TBP was present in the organic phase, but metals dissolved in both phases retarded degradation slightly. Products in tests where $\sim 10 \%$ of the DEB was degraded depressed uranium extraction slightly, decreased the rate of phase disengagement from acidic and alkaline solutions by a factor of 2 , did not change the solvent flash point. No satisfactory method of product removal from the organic phase was developed but additional testing is needed to determine rate of buildup during actual processing. Measurement of the heat of degradation of solvents in a new adaptation of the method of differential thermal analysis is described and it is shown how this method should be useful in estimating the requirements of processing apparatus to dissipate heat evolved during degradation. The calculations show little effect of 2 watt hr/1 DEB exposure on extraction column temperature, or of degradation of entrained $\mathrm{DEB}$ in aqueous phases being concentrated by evaporation. Commercial diisopropylbenzenes and detergent "alkylates" are less stable than DEB. Data are included which summarize the ORNL observations which pertain to the stability of some extraction reagents, e.g., amides, amines, phenols, and a dialkyl phenylphosphonate.

\footnotetext{
*Research sponsored by the U. S. Atomic Energy, Commission under contract with the Union Carbide Corporation.
} 


\title{
STABILITY OF AROMATIC DILUENTS AND SOLVENT EXTRACTION REAGENTS IN RADIOCHEMICAL PROCESSING*
}

\author{
Charles A. Blake, Jr. and J. M. Schmitt \\ Oak Ridge Nationa 1 Laboratory \\ Oak Ridge, Tennessee
}

\section{INTRODUCTION}

Interest in aromatic diluents stems from results of ORNL studies ${ }^{2}$ which showed that significant improvement in the performance of a variety of solvent extraction-metal recovery processes would be realized if the commonly used TBP-aliphatic diluent combinations could be replaced with TBP-aromatic combinations. The benefits from such a change could include increased TBP extraction power, improved solubility properties of some of the extracted TBP-metal complexes, more highly selective extraction of uranium and other metals, and increased TBP stability against radiation-enhanced chemical degradation. Little was known, however, about the behavior of the aromatic diluents themselves during radiochemical processing. For example, it was not known which structural types were most useful, or which, if any, were suitably stable, or what degradation products are formed, or how such products and their formation might affect solvent properties, including safety.

\footnotetext{
*Research sponsored by the U. S. Atomic Energy Commission under contract with the Union Carbide Corporation
} 
In 1962 a study at ORNL had just been finished of some of the factors involved in determining the suitability of aliphatic diluents for use in radiochemical processing. This program was reoriented to incorporate testing of aromatic diluents, and preliminary evaluations of the stabilities of some samples of alkylbenzenes, that were then were

available, presented at Gatlinburg in $1962 .{ }^{2}$ It was evident (Table 1) that several of the simple alkylbenzenes** compared favorably with $\underline{n}-$ dodecane (the aliphatic standard) with respect to resistance to formation of fission product extracting degradation products when heated together with nitric acid. But fission product extraction power is only one measure of diluent degradation; indeed, because of its sensitivity to trace impurities, it is probably not the best test if it is desired to evaluate completely the performance of diluents of different structure. The poor showing of Solvesso 100 (Table 1), is, for example, due to a large extent to compounds other than its principle constitutents, which here are predominately $C_{10}$ and $C_{11}$ alkyl benzenes.

A significant change in the diluent price structure has occurred since 1962. "Straight chain" a1kylbenzenes in the dodecylbenzene range are now approaching costs of $\$ 0.75$ per gallon because of their use in large-scale production of biodegradable detergents. Since the $\underline{\text { n-alkyl- }}$ benzenes performed well in the tests of Table 1, it was hoped that these

* *andidates for future use as aromatic diluents are the liquid tetramethylbenzenes, prehnitene and isodurene (Table 1), which are not yet commercially available, although there is considerable interest in the polymethylbenzenes. Durene, a solid symmetrical tetramethylbenzene is now aviailable. 
TABLE 1. PERFORMANCE OF DEGRADED DILUENTS

\begin{tabular}{|c|c|c|}
\hline Diluent & $\begin{array}{c}\text { Flash point } \\
(\text { closed cup }) \\
\left({ }^{\circ} \mathrm{F}\right)\end{array}$ & 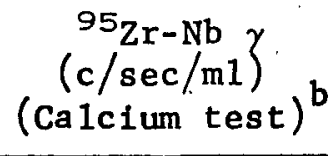 \\
\hline \multicolumn{3}{|c|}{ Alky1 Benzenes } \\
\hline Methyl (toluene) & 40 & 110 \\
\hline 1,2-Dimethy1 (o-xylene) & 63 & 100 \\
\hline 1,3-Dimethy $1(\underline{m}-x y 1$ ene $)$ & 63 & 100 \\
\hline 1,4-Dimethy1 (p-xylene) & 63 & 100 \\
\hline $\begin{array}{l}\text { 1,2,4-TrimethyT (pseudo- } \\
\text { cumene) }\end{array}$ & 125 & 100 \\
\hline $\begin{array}{l}\text { 1,2,3-Trimethy1 (hemime1- } \\
\text { litene) } 73 \%\end{array}$ & 124 & 400 \\
\hline $96 \%$ & & $>6000$ \\
\hline $\begin{array}{l}1,2,3,4-\text { Tetramethy } 1 \text { (prehn- } \\
\text { itene) }\end{array}$ & $163^{\mathrm{a}}$ & 200 \\
\hline $\begin{array}{l}1,2,3,5-\text {-Tetrame thyl (iso- } \\
\text { durene). }\end{array}$ & $155^{\mathrm{a}}$ & 1400 \\
\hline Ethy 1, & $59 a$ & .500 \\
\hline $\begin{array}{l}\text { Diethy1 (mixtures) } \\
\text { Triethy1 (mixture) }\end{array}$ & $138^{\mathrm{a}}$ & 4000,10000 \\
\hline Propy1 & 86 & 80,450 \\
\hline Isopropy 1 (cumene) & 102 & 30,4000 \\
\hline Diisopropyl (mixture) & 170 & $\$ 600$ \\
\hline Triisopropy 1 & 170 & $>6000$ \\
\hline n-Buty1 & $160^{\mathrm{a}}$ & 125 \\
\hline sec-Buty1 & 126 & 130 \\
\hline$\overline{\text { tert }}$-Butyl & $140^{\mathrm{a}}$ & 120 \\
\hline iso-Buty1 & & 45 \\
\hline Tetralin & 171 & decomposes \\
\hline $\begin{array}{l}\text { 1-Methy1-4-isopropy1 (para- } \\
\text { cymene) }\end{array}$ & 138 & 4000 \\
\hline$\underline{\text { sec-Amy } 1}$ & $\sim 150^{\mathrm{a}}$ & 170 \\
\hline$\frac{\text { tert-Amy } 1}{\text { propy } 1)}(1,1$-dimethy $1-$ & & 130 \\
\hline$\underline{\mathrm{n}}-$ Hexy 1 & & 120 \\
\hline Cyclohexy1 & & $>6000$ \\
\hline$\underline{n}$-Nony 1 & & 180 \\
\hline Solvesso- 100 & 118 & $>6000$ \\
\hline Solvesso- 150 & 150 & $>6000$ \\
\hline \multicolumn{3}{|c|}{ Aliphatic Hydrocarbons } \\
\hline Amsco $125-82$ & 128 & 4000 \\
\hline $\begin{array}{l}\text { Amsco } 125-82\left(\mathrm{H}_{2} \mathrm{SO}_{4}\right. \\
\text { scrubbed })\end{array}$ & 128 & 100 \\
\hline n-Dodecane & 165 & 125 \\
\hline
\end{tabular}

a Open cup.

bee "Experimenta 1 Methods". 
"alkylates" would be useful diluents. Brief investigation of some commercial products has, however, shown them to be mixtures of $20-30$ compounds some of which degrade readily on contact with nitric acid.

Most of the detailed studies described in this paper have been made on diethylbenzene (DEB) because: (1) It is probably the simplest of the commercially available high-flash point-aromatic diluents, can be obtained reasonably free from other compound, and costs $\$ 1.40$ per gallon; (2) Some of the commercial batches give low fission product extraction after degradation with nitric acid; (3) The separated and purified DEB isomers are available for individual study. The first portion of the paper describes and compares degradation of commercial and purified DEB's by nitric acid in the presence or absence of ionizing radiation, with and without TBP present in the organic phase and with and without metals in both phases. Then follow sections which present the methods used to identify the principle degradation products and the effects which the products have on extraction properties and solvent flash point. Comments about solvent clean-up experiments are included. Measurement of the heat of degradation of DEB in a new adaptation of the method of differential thermal analysis is described and it is shown how this method should be useful in estimating the requirements of processing apparatus to dissipate heat evolved during the degradation. Finally, data are included which describe the poor stability of commercial detergent alkylates and difopropyl benzenes and summarize the ORNL observations which pertain to the stability of some extraction reagents, e.g., amides, amines, phenols and a didkyl phenyl phosphonato. 


\section{EXPERIMENTAL METHODS}

Two methods were employed to degrade the solvent phases: (1) A 6000 curie cobalt source was used to irradiate an agitated 2-phase system, the aqueous phase being initially $2 \mathrm{M} \mathrm{HNO}_{3}$, and the radiation power being approximately 1 watt/1iter; (2) The solvent was boiled under tota 1 reflux with aqueous acid, the agitation being accomplished by the boiling. The acid was $2 \mathrm{M} \mathrm{HNO}_{3}$ except for one test series with chloride solutions.

TBP was present during many of the degradations. Since the interest was primarily with the diluent and its properties, the degraded solvent was usually scrubbed with $0.2 \mathrm{M} \mathrm{Na}_{2} \mathrm{CO}_{3}$ to remove the low molecular weight acid products derived from TBP. Such scrubbing restores TBP, degraded by either of the above methods, nearly to its original extraction behavior as measured in the present test procedure.

The degraded solvent was examined by several techniques; measurement of metal extraction ability, gas liquid chromatography (GLC), column chromatography, distillation, infra red (IR) and nuclear magnetic resonance (NMR) spectrometry, differential thermal analysis (DTA), and elemental analyses.

In metal extraction tests the degraded solvent is customarily used to extract ${ }^{95} \mathrm{Zr}-\mathrm{Nb}$ or ${ }^{181} \mathrm{Hf}$, from aqueous $\mathrm{HNO}_{3}$, and the ability of the extracted metals to withstand subsequent scrubbing with $\mathrm{HNO}_{3}$ is one of the common measures of degradation. However, it has been observed at ORNL that the curves showing metal ion extraction and those showing retention ability are nearly always parallel when using the test proce- 
dure described below. To simplify the presentation of data, only the metal extraction ability of the solvent is described in this paper. Extraction test procedure (calcium test): (1) Make the degraded solvent $1 M$ in TBP and scrub twice with an equal volume of $0.2 \mathrm{M}$ aqueous $\mathrm{Na}_{2} \mathrm{CO}_{3}$ to remove low-molecular-weight acids, primarily DBP and MBP (10 min each contact); (2) Contact 30 min with solid calcium hydroxide, $50 \mathrm{~g}$ solid/1iter of organic phase, and separate from solid; (3) Contact with metal tracer solution (e.g., ${ }^{181} \mathrm{Hf}$ ) in nitric acid solution and measure the extraction. An equal volume of tracer solution containing $10^{4} \mathrm{y} \mathrm{C} / \mathrm{sec} \mathrm{ml}$ in $2 \mathrm{M} \mathrm{HNO}_{3}$ is customarily used. Extraction power is given in terms of the distribution coefficient, $\underline{D}$, or of the $\gamma$ activity reporting to the organic phase.

In gas chromatography an Aerograph Autoprep Mode1 A-700 (Wilkins Instrument and Research, Inc.) gas chromatograph (heated metal filament detector) equipped with an $\mathrm{L}$ and $\mathrm{N}$ Speedomax $\mathrm{H}$ recorder was used in this work. The column was copper and $1 / 4$ inch $x 10-20$ feet long with a packing of 20\% Dow Corning SE-30/Chromosorb W-HMDS.

Elemental analyses were performed by the ORNL Analytical Division. IR and NMR measurements were made on Beckman IR7 and Varian A-60 instruments, respectively.

Differential thermal analyses (DTA) were made by comparing temperatures in two tubes immersed in a stirred oil bath equipped with a programmed heater. The test media are described in a later section. 
3. STABILITY OF BATCHES OF COMMERCIAL DEB AND PURIFIED DEB ISOMERS

The studies described in the following sections are all of the stability of DEB and associated impurities against attack by nitric acid. Tests in which DEB was boiled with hydrochloric acid and chloride salts showed no degradation, e.g., DEB boiled with 6M HC1 for 48 hr gave no evidence of by-product formation in GLC tests, and chloride uptake by the treated DEB was not detected by a method in which 1 atom of chlorine in 1000 molecules of $\mathrm{DEB}$ would have been found.

Tracer Extraction Tests. Wide variations were observed in comparisons of $\mathrm{HNO}_{3}$-degraded commercial DEB mixtures by the metal ion extraction test procedure (e.g., Table 1). These and other DEB mixtures varied in composition (50-60\% meta-DEB, 25-40\% para-DEB, 5-10\% ortho-DEB, 5-10\% other compounds related in structure). Empirica11y, their stabilities, as measured by extraction power after degradation, decreased as the percentage of meta-DEB decreased. ${ }^{3}$ Deviations from this rather simple picture were shown, however, when a previously untested commercial DEB and some, but not a11, batches of each of the separated isomers gave low tracer extraction when degraded (Table 2). In brief gas chromatographic examination it was not possible in different lots of the same material to distinguish differences which related to the tracer extraction data. It is apparent that high tracer extraction is related primarily to impurities and that these impurities may associate more with para- and ortho-DEB isomers than with meta-DEB. In further testing of this hypothesis the poorly stable D-62 DEB (Table 2) was degraded with $2 \mathrm{M} \mathrm{HNO}_{3}$ for 4 hours, then distilled to 
TABLE 2. COMPARISON OF SEVERAL DEB'S AFTER DEGRADATION ${ }^{a}$

\begin{tabular}{|c|c|c|c|}
\hline \multirow[b]{2}{*}{ DEB } & \multirow[b]{2}{*}{ SAMPLE } & \multicolumn{2}{|c|}{ Calcium Test ${ }^{b}$} \\
\hline & & $\begin{array}{l}{ }^{95} \mathrm{Zr}-\mathrm{Nb} \gamma \\
(\mathrm{c} / \mathrm{s} / \mathrm{m} 1)^{\gamma}\end{array}$ & $\begin{array}{c}{ }^{181} \text { Hafnium } \\
\text { Distribution } \\
\text { Coefficient }\end{array}$ \\
\hline \multirow[t]{3}{*}{ COMMERCIAL } & $D-26$ & $>6000$ & 3.3 \\
\hline & $D-62$ & .4000 & 0.1 \\
\hline & $D-103$ & 65 & 0.004 \\
\hline \multirow[t]{2}{*}{ ORTHO } & $D-76-A$ & - & 0.1 \\
\hline & D-106 & - & 0.82 \\
\hline \multirow[t]{3}{*}{ META } & $D-76-C$ & 100 & 0.001 \\
\hline & $D-102-A$ & 120 & 0.0005 \\
\hline & $D-105$ & 200 & 0.0013 \\
\hline \multirow[t]{3}{*}{ PARA } & $D-76-B$ & $\varnothing 6000$ & $>1$ \\
\hline & D-102-B & 680 & 0.0012 \\
\hline & $D-107$ & 4000 & 0.1 \\
\hline
\end{tabular}

${ }^{1}$ M TBP in DEB boiled under reflux for $4 \mathrm{hr}$ with an equal volume of $2 \mathrm{M} \mathrm{HNO}_{3}$.

$b_{\text {Extraction from }}{ }^{181} \mathrm{Hf}$ or ${ }^{95} \mathrm{Zr}-\mathrm{Nb}$ tracer solutions, $10^{4} \mathrm{\gamma} \mathrm{c} / \mathrm{sec} /$ $\mathrm{ml}$, equal volumes organic and aqueous phases, after scrubbing degraded organic twice with an equal volume of $0.2 \mathrm{M}$ aqueous $\mathrm{Na}_{2} \mathrm{CO}_{3}$ and contacting scrubbed organic for $30 \mathrm{~min}$ with solid calcium hydroxide. 
recover undegraded DEB. This cycle was repeated 3 times. Samples of the initial material and each of the distilled products were made to IM with TBP and then subjected to the standard degradation test. The hafnium extraction coefficient decreased from an initial $D=3.3$, to 1.1 , 0.25 and finally to $D=0.13$. Initially, the ratio of isomers was (GLC) meta:para: ortho $=1: 0.83: 0.24$. The final ratio, $1: 0.69: 0.24$, showed a preferential decomposition of the para isomer or more likely, of material which reported with the para-DEB in the gas chromatogram. It was not possible, however, to resolve the apparent para-DEB GLC peak into more than 1 component of use by a GLC column specially developed to resolve DEB isomers ${ }^{3}$.

The nitrogen analysis of each of the degraded solutions before distillation was essentially constant at $0.35 \mathrm{M}$ and represents nitration, on the average, of 1 mole of $\mathrm{DEB}$ for each 18 originally present. Since the hafnium distribution coefficients were independent of the nitrogen uptake, it became apparent that additional test methods were required to elucidate the degradation scheme.

Comparison of Degradation by Boiling and Irradiation. Gas chromatograms after meta-DEB degradation by $2 \underline{M} \mathrm{HNO}_{3}$ with and without irradiation are nearly identical (Fig 1). Six or more degradation products are apparent and 3 of these (peaks 3,4 and 5) predominate. Two of these 3 products (identified by methods described in a later section) are: 3-ethylacetophenone, (4); and 1-nitroethy1-3-ethylbenzene, (5).<smiles>CCc1cccc(C(C)=O)c1</smiles><smiles>CCc1cccc(C(C)[N+](=O)[O-])c1</smiles> 
Together with a small amount of ethylbenzoic acid isolated from the aqueous phase, the 3 products account for greater than $95 \%$ of both the total degradation and the nitrogen uptake. Chromatograms of degraded para- and ortho-DEB' are similar to those of Figure I in numbers of products and in their distribution. Ortho-DEB isomer products emerge from the column about $5 \%$ faster than their meta-DEB counterparts, para-DEB isomers emerge about $7 \%$ slower.

Degradation vs. Time. The true extent of degradation and increase in concentration of individual degradation products have been followed principally by quantitative gas chromatography and, to a smaller extent, by analysis of the nitrogen uptake by the degrading solvent phase. A composite representation of data obtained by both methods is shown on Figure 2 for each of the DEB isomers when degraded separately by boiling with $2 \mathrm{M}^{2} \mathrm{HNO}_{3}$ under reflux. About 5 and $20 \%$ meta-DEB decomposed after 5 and 10 hours boiling, respectively, and about twice as much of each of the ortho- and para-DEB's degraded in the same time intervals. (In these tests the aqueous $\mathrm{HNO}_{3}$ concentration was maintained at $2 \underline{M}$ by periodic replacement of the depleted acid).

The isomers of $\mathrm{DEB}$, degraded with $\mathrm{HNO}_{3}$ in the presence of ${ }^{6 \circ} \mathrm{Co}$ irradiation, were analyzed similarly and the data are shown in Figure 3 . The curves are those of Figure 2 drawn on the expanded scale shown at the top of Figure 3. The irradiation dose scale at the bottom of Figure 3 was arbitrarily adjusted to make the meta-DEB chemical damage curve fit the meta-DEB radiation damage data. The para-DEB radiation data fit the upper curve nicely at 35 watt $h r / 1$ dosage but then fall 
off. The ortho-DEB radiation damage data are everywhere lower than the corresponding chemical damage curve. Gas chromatograms showed that radiation and chemical damage produce the same products, but apparently at rates which differ with the isomer. Damage observed at 70 watt $\mathrm{hr} / 1$ is, for example, equivalent to boiling the meta-DEB for $5 \mathrm{hr}$, the para-DEB for $4 \mathrm{hr}$ and the ortho-DEB for $2 \mathrm{hr}$.

The distribution of products changes with increased degradation. At the highest exposures compounds 4 and 5 predominate. Compound 3 reached a maximum concentration (at about $5 \mathrm{hr}$ boiling for meta-DEB) and then decreased.

Degradation in the Presence of TBP. Diethylbenzenes degrade 2 to 5 times faster with $\mathrm{HNO}_{3}$ when TBP is present in the organic phase during the treatment (Table 3). As in the case with aliphatic diluents ${ }^{2}$, this is probably because of nitrate and nitrite extraction by the TBP. When a $1 \mathrm{M}$ TBP solution in $\underline{\mathrm{n}}$-dodecane was irradiated to $70 \mathrm{whr} / 1$ in a test procedure identical to that used to obtain the data of Table 3, the organic phase nitrogen concentration was $0.25 \mathrm{M}$, which is equivalent to 0.078 moles $\mathrm{N} / \mathrm{mole}$ dodecane.

Degradation in the Presence of Dissolved Metals. A commercial DEB (D-116), $1 \mathrm{M}$ in $\mathrm{TBP}$, was mixed with an aqueous $2 \underline{\mathrm{M}} \mathrm{HNO}_{3}$ solution containing dissolved metals and the stirred 2-phase system was irradiated. The object of the experiment was to simulate in laboratory tests a condition more nearly approximating the conditions prevailing in large plant processing equipment. Periodic analyses of the organic phase 
TABLE 3. COMPARISON OF DEB DEGRADATION BY $\mathrm{HNO}_{3}$ DURING IRRADIATION WITH AND WITHOUT TBP

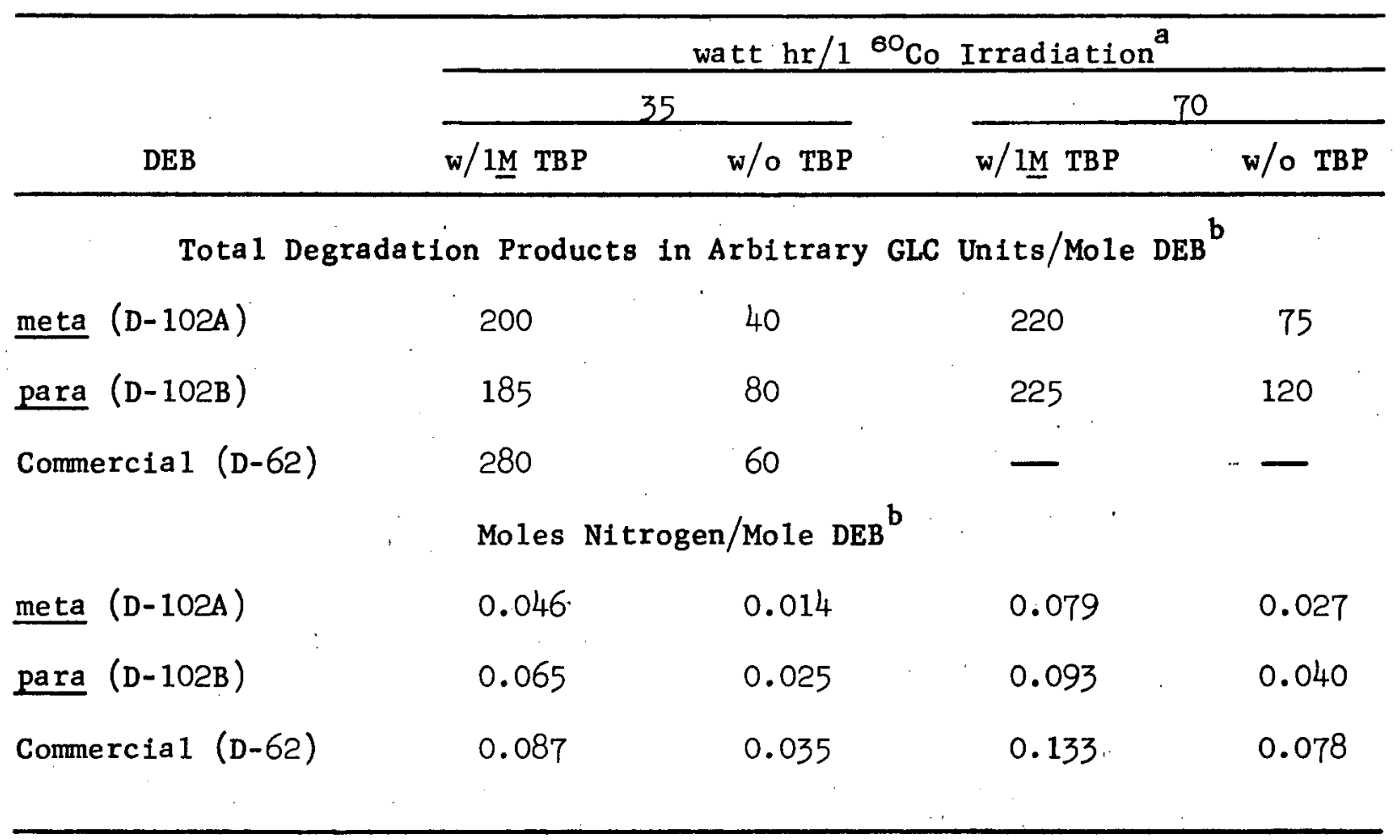

${ }^{a}$ While stirring with $2 \underline{M} \mathrm{HNO}_{3}$, dose rate $=1.5$ watt $/ 1$

$\mathrm{b}_{100 \% \mathrm{DEB}}=6.4 \underline{\mathrm{M}}, \mathrm{DEB}=4.6 \mathrm{M}$ in $1 \mathrm{M} \mathrm{TBP} / \mathrm{DEB}$ 
and that from a control test without metals present showed that the rate of DEB degradation was slightly lower in the presence of the metals (Table 4).

\section{ISOLATION AND IDENTIFICATION OF MAJOR DEGRADATION PRODUCTS}

Very little previous study has been made of the reactions of DEB with dilute nitric acid. Voswinke1, e.g., ${ }^{4}$ describes formation of ethyl benzoic acids and phthallic acids, but no reference was found which described substitutions on the side chains. Methylisopropy 1 benzene is reported, 5 however, to give methy 1 acetophenone when treated with dilute nitric acid, and 1-nitroethylbenzene has been prepared ${ }^{6}$ from ethylbenzene. Since IR spectra of degraded DEB showed strong absorption at wave lengths corresponding to side chain ketone and nitro groups these seemed strong clues to the likely degradation product structures. Little nitration of the benzene ring itself was expected, 5,6 and IR spectra of degraded DEB confirmed this expectation.

Because the sma 11 amount of major DEB products were resolved by GLC (Fig 1), it was hoped that preparative gas chromatography could be used for their separation and identification. To provide suitable feeds for the operation a concentrate of para-DEB degradation products was prepared as follows:

$100 \mathrm{~g}$ para-DEB were mixed with boiling $2 \mathrm{M} \mathrm{HNO}_{3}$ for $16 \mathrm{hr}$. GLC analysis showed that about $45 \%$ of the para-DEB degraded in this time and that the principle products of this severe treatment were most probably the para-DEB analogs of compounds 4 and 5 of (Fig 1). The as-degraded materia 1 was scrubbed with an equal volume of $1.0 \mathrm{M} \mathrm{NaCO}_{3}$ (Subsequently about 1-2 $g$ of material tentatively identified as ethyl- 
TABLE 4. DEGRADATION OF 1M TBP/DEB IN THE PRESENCE OF DISSOLVED METALS

\begin{tabular}{|c|c|c|}
\hline \multirow{2}{*}{$\begin{array}{c}{ }^{80} \text { Co Dose }{ }^{a} \\
(\text { whr } / 1)\end{array}$} & \multicolumn{2}{|c|}{ IM TBP/DEB Degraded by 2 M $\mathrm{HNO}_{3}$} \\
\hline & Without Metals & With Metals \\
\hline \multicolumn{3}{|c|}{ Tota 1. Products by GLC-Arbitrary Units } \\
\hline 23 & 210 & 210 \\
\hline 47 & 420 & 400 \\
\hline 70 & 590 & $470^{b}$ \\
\hline \multicolumn{3}{|c|}{ Tota 1 Degraded DEB $(\phi)$} \\
\hline 70 & 11 & 10 \\
\hline
\end{tabular}

$a_{\text {Dose rate }}=1.0 \mathrm{w} / \mathrm{hr}$

bquilibrium metal concentrations

Organic phase: Tota 1 meta1s $=0.11 \mathrm{M},(0.098 \mathrm{M} \mathrm{U}, 0.0085 \mathrm{M} \mathrm{Fe}$, $0.0155 \underline{\mathrm{M}} \mathrm{Zr})$

Aqueous phase: Total metals $=0.153 \mathrm{M},(0.0059 \underline{\mathrm{M}} \mathrm{U}, 0.11 \mathrm{M} \mathrm{Fe}$, $0.037 \mathrm{Mr}$ ) 
benzoic acid was recovered from the bicarbonate solution). The washed material was then distilled under vacuum $(\sim 0.5 \mathrm{~mm} \mathrm{Hg})$ with the following fractionations being made:

IBP to $70^{\circ} \mathrm{C}$ (predominantly DEB); $70-100^{\circ} \mathrm{C}$ (predominantly ketone); $100-132^{\circ} \mathrm{C}$ (predominantly nitro compound). About $5 \%$ of the initial $100 \mathrm{~g}$ samples remained as pot residue.

Ethy1-Acetophenone (Compound 4). The $70-100^{\circ} \mathrm{C}$ fraction was then further fractionated on a $20 \mathrm{ft}$ column in the GLC $(\xi 2.0)$. Severa 1 grams of product were prepared which gave a strong IR ketone band much like that for acetophenone at $\underline{1680}$ wave numbers. The equivalent weight of the ketone was determined to be approximately 154 and this with the elementa 1 analysis indicated $\mathrm{C}: \mathrm{H}: 0$ ratios of $9.5: 12.1: 1.0$. The actua 1 analyses and the theoretica 1 analyses for 4 -ethyl-acetophenone $(\mathrm{C}: \mathrm{H}: 0=$ 10:12:1) are given below:

Percent

Peak 3 4-Ethy1-Acetophenone

$\begin{array}{lrr}\text { Carbon } & 81.2 & 81.1 \\ \text { Hydrogen } & 7.9 & 8.2 \\ \text { Oxygen } & 10.5 & 10.8\end{array}$

A sample of 4-ethyl-acetophenone was obtained from Eastman Kodak Company and the material appeared to be identical to the isolated material in GLC tests.

1-Nitroethy 1-4-ethylbenzene (Compound 5). Attempts by GLC to prepare pure material from the $100-132^{\circ} \mathrm{C}$ distillation fraction corresponding to peak 5 (Fig 1) were not successful. The product always contained appreciable amounts of the 4-ethylacetophenone from the thermal 
decomposition of the nitro compound. Separation was, however, made by the technique of column chromatography. The sample was diluted in petroleum ether and added to the top of a $30 \mathrm{~cm} \mathrm{x} 1 \mathrm{~cm}$ column of neutral alumina wet with petroleum ether. Washing with petroleum ether removed the small amount of DEB initially in the sample and washing with benzene eluted the nitro compound. The ketone and other products remalned on the column. The NMR spectrum of the sample after evaporation of the petroleum ether gave excellent confirmation of the 1-nitroethy1-4-ethylbenzene structure. Elemental analyses verified the expected mole ratios of $\mathrm{C}: \mathrm{H}: 0: \mathrm{N}=10: 13: 2: 1$. Some of the product was sealed into a sma11 vial which was then heated at $110^{\circ} \mathrm{C}$ for $11 / 2 \mathrm{hr}$. Gas chromatograms of the heated material showed that $25 \%$ of the nitro compound had become 4-ethy1acetophenone. An additiona $11 / 2 \mathrm{hr}$ heating transformed another $25 \%$ of the nitro compound. This explains the difficulty of purifying the nitro compound by GLC and is further confirmation of the structure of the two compounds .

Other Products. Brief examination of silica gel and neutral alumina with their elutropic series (petroleum ether, benzene, diethy1 ether, acetone, methy1 alcohol) showed that resolutions of the other and less significant degradation products of DEB were possible. It appeared that materials which could not be eluted from the packed column by the solvents amounted to less than $2 \%$ of the initia1 DEB sample before degradation.

\section{EFFECT OF DEGRADATION PRODUCTS ON THE EXTRACTION PROCESS}

Extraction Power. Degradation products from pure DEB's have a1ready been shown to be poor extractants for ${ }^{95} \mathrm{Zr}-\mathrm{Nb}$ and ${ }^{181} \mathrm{Hf}$ (Table 2 ). 
Insufficient supply of the compounds has limited further examination of their fission product extraction power. In a few uranium extraction tests (Table 5) the nitro and ketone products showed very low uranium extraction ability when used alone. In combination with TBP the pure compounds depressed uranium extraction slightly as did degrading a $1 \mathrm{M} \mathrm{TBP} / \mathrm{DEB}$ solution. The concentration of products used and the $4 \mathrm{hr}$ 's boiling given the IM TBP/DEB solution are equivalent to severe degradation of the organic phase.

Phase Separation. The presence of degradation products of DEB and its impurities in an extractant phase has an adverse effect on disengagement from aqueous phases. For example, a $1 \mathrm{M}$ TBP/DEB solution degraded by boiling with $2 \mathrm{M}^{2} \mathrm{HNO}_{3}$ for $4 \mathrm{hr}$ takes about twice as long as the undegraded solution to separate at room temperature from $2 \mathrm{M} \mathrm{HNO}_{3}$ (90 sec vs $45 \mathrm{sec})$ and from $0.2 \mathrm{M} \mathrm{Na} \mathrm{NO}_{3}(60 \mathrm{sec}$ vs $30 \mathrm{sec})$.

Flash Point. The closed cup flash points of degraded and fresh 1M TBP/DEB were essentia11y the same:

Fresh 1M TBP/DEB

Degraded 1M TBP/DEB

( 70 watt $\mathrm{h} \overline{\mathrm{r}} / 1{ }^{60} \mathrm{Co}$ exposure while stirring with $2 \mathrm{M} \mathrm{HNO}_{3}$ )
Flash Point (c.c.) $=136-138^{\circ} \mathrm{F}$

Flash Point (c.c.) $=135-136^{\circ} \mathrm{F}$

Solvent Cleanup. DEB of proper purity should present no more difficulty from the standpoint of unwanted fission product extraction than that encountered in use of $\underline{n}$-dodecane $(\S 5.1$ and Table 2$)$. As is the case with aliphatic diluents, it is difficult to remove completely 
TABLE 5. EFFECT OF DEGRADATION PRODUCTS ON URANIUM EXTRACTION

\begin{tabular}{|c|c|}
\hline Extractant Phase & $\begin{array}{l}\text { mistribution Coefficient } \\
\text { from } \\
2 \underline{M} \mathrm{HNO}_{3}, 0.004 \underline{\mathrm{M}} \mathrm{U}(\mathrm{VI})\end{array}$ \\
\hline $1 \mathrm{M} \mathrm{TBP}$ in $\mathrm{DEB}$ & 24 \\
\hline $\begin{array}{l}\text { IM TBP in } \mathrm{DEB}^{\mathrm{a}} \\
\text { Degraded } 4 \mathrm{hr}, 2 \mathrm{M} \mathrm{HNO}_{3} \text { (boiled) }\end{array}$ & 19 \\
\hline $\begin{array}{l}\text { 1M TBP in DEB } \\
0.4 \mathrm{M} 1 \text {-Nitroethy } 1-4-\text { ethy } 1 \text { benzene }\end{array}$ & 21 \\
\hline $\begin{array}{l}\text { 1M TBP in DEB } \\
0.5 \mathrm{M} 4-\mathrm{E} \text { thylacetophenone }\end{array}$ & 23 \\
\hline $0.4 \mathrm{M} 1$-Nitroethy $1-4-$ ethy 1 benzene in DEB & $10^{-2}$ \\
\hline $0.5 \mathrm{M}$ 4-Ethylacetophenone in $\mathrm{DEB}$ & $10^{-5}$ \\
\hline
\end{tabular}

${ }^{a}$ Nitrogen analysis of the organic phase after degradation $=0.48 \underline{M}$ 
the DEB degradation products from the organic phase. Scrubbing with water and aqueous alkaline solutions ( $\left.\mathrm{NaOH}, \mathrm{LiOH}, \mathrm{Na}_{2} \mathrm{CO}_{3}\right)$ removes some of Compound 5, but is ineffective in Compound 4 remova1. Scrubbing with ethanolamine efficiently removes most of Compound 5, but this method of cleanup is subject to the same limitations previously noted. 2 (Expense, loss of TBP, distribution of ethanolamine to the organic phase). Further testing is required to determine the extent of product buildup in a continuous process and whether such buildup actually constitutes a problem.

Measurement of the Heat of Diluent Degradation by Differential Therma1 Analysis. When a diluent is used in a solvent extraction process it is imperative to know whether its degradation may involve hazardous chemical reactions or products which are explosively unstable under process conditions. Much of the solvent study here and elsewhere has been concerned primarily with the degree of degradation of various diluents, and little attention has been paid to developing hazard evaluation test procedures. Differential thermal analysis (DTA) has been used recently ${ }^{7}$ to determine quantitatively the kinetic parameters for certain types of reactions and it seemed likely that DTA might be used to measure heat evolved during diluent degradation. With the help of W. H. Baldwin of the ORNL Chemistry Division, a system was developed which would permit heating mixtures of either aliphatic or aromatic diluents, tributyl phosphate, nitric acid, and water in a single phase. Nitrobenzene, which did not react with any of these components under the conditions of the test was used as the solvent. Gas chromatograms 
of the DTA degraded para-DEB and DEB degraded by boiling with $2 \underline{M} \mathrm{HNO}_{3}$ were an indication that the decomposition reactions were similar even though the conditions for degradation were very different. The quantity of DEB degrading during the DTA test was estimated from the chromatograph and the heat evolved during its decomposition was estimated from the thermograph. It was concluded that the heat of degradation of para-DEB with dilute nitric acid is $50-70 \mathrm{kca} / \mathrm{mole}$. (In comparison, the heat of nitration of benzene to nitrobenzene is $27 \mathrm{kcal} / \mathrm{mole}$, the heat of oxidation of hydrogen to water is $58 \mathrm{kca} 1 / \mathrm{mole}$, and the heat of solution of hydrochloric acid is $17 \mathrm{kca} 1 / \mathrm{mole.}$ In paralle1 testing di-iso-propyl benzene gave a heat of degradation of about 40 $\mathrm{kca} 1 / \mathrm{mole}$. Exothermic degradation in tests with n-dodecane was observed on the thermograms, but the total material degraded was too sma11 to enable determination of the heat of reaction.

In another application of DTA, some concentrated DEB degradation products (the sti 11 pot residue from a vacuum distillation of nitric acid degraded DEB) were sorbed on alumina and heated. Exothermic reaction began at $160^{\circ} \mathrm{C}$.

It seems 1ikely that with further refinements of the DTA techniques this method could prove a useful adjunct to evaluation of diluent qua 1ity and stability. Assume, for example, that $1 \mathrm{M}$ TBP-DEB solvent phase (4. TM DEB) is exposed to a high radiation dose equivalent to 2 watt $\mathrm{hr} / 1$. Fig 3 and Table 3 indicate that between 0.15 and $0.3 \%$ of the DEB would be degraded with a release of 500 to 1000 cal from each liter of organic phase (using $70 \mathrm{kcal} / \mathrm{mole}$ DEB). Some of this heat will be dissipated in the aqueous phase with which the organic phase is being mixed, but 
neglecting this and assuming a specific heat of 0.4 for the organic phase, its temperature could increase by 1.5 to 3 degrees. Further assume that $0.5 \mathrm{m1}$ of a $1 \mathrm{M} \mathrm{TBP} / \mathrm{DEB}$ organic phase is entrained in 1 liter of aqueous phase which is to be concentrated 10-fold by evaporation. The heat evolved if the DEB were totally decomposed would amount to $\sim 1600 \mathrm{cal}$ per liter of concentrate, an amount which is sma11 compared to the quantity of heat being supplied to sustain the evaporation.

\section{STABILITY OF OTHER COMMERCIALLY AVAILABLE ALKYLBENZENES}

Two additiona 1 alkylbenzene products are available commercially in quantity, i.e., "detergent alkylates" (alkylbenzenes prepared from $\alpha$-olefins in the $\mathrm{C}_{9}$ to $\mathrm{C}_{14}$ range) at less than $\$ 1.00 /$ gallon, and disopropylbenzene at less than $\$ 1.40 /$ gallon. Their poor stability against attack by $\mathrm{HNO}_{3}$ does not at this time make attractive their use as diluents in radiochemical processing of nitrate solutions, but this does not preclude their use in other systems.

Stability of Alkylbenzenes made from Alpha-0lefins. Production of biodegradable detergents has made alkylbenzenes (alkylates) derived from straight-chained $\alpha$-olefins available in quantity at prices competitive with $\underline{n}$-dodecane or DEB. Three commercially available products, each prepared from $\alpha$-olefins in the $C_{9}$ to $C_{14}$ range were examined with regard to their stability toward nitric acid degradation. As indicated by a high organic phase nitrogen concentrationi and a contribution to high ${ }^{181} \mathrm{Hf}$ extraction, each of these products was found to degrade 
severely when boiled for 4 hours with $2 \mathrm{M} \mathrm{HNO}_{3}$. This behavior is in contrast to that of n-octylbenzene which had good stability under the same conditions (Table 6). Extraction of ${ }^{181} \mathrm{Hf}$ considerably higher than those given in Table 6 was obtained when the degraded alkylates were contacted with the solid $\mathrm{Ca}(\mathrm{OH})_{2}$ for a time longer than the 30 min specified in the calcium test or when the materials were scrubbed repeatedly with $1 \mathrm{M}$ LiOH. In the case of alkylate D-111 extraction increased from $D=0.07$ after the first contact to $D=14$ after the fourth contact. It is apparent that the rate at which the degradation products are converted to their most extracting form is much lower than that for DEB degradation products.

Examination by gas chromatography of the alkylates used in these tests showed each to have at least 17 components. 0 ther workers $^{8}$ have shown that while $\alpha$-olefins were used in the synthesis of the alkylates, most of the products were secondary alkylbenzenes and that a high percentage of these had phenyl substitution on the interior carbon atoms of the olefin. No n-alkylbenzenes were observed and a significant amount $(\sim 10 \%)$ of more highly branched isomers and other hydrocarbons were found. Such branching provides foca 1 points for attack by $\mathrm{HNO}_{3}$ and explains the observed instability. It is possible that some pretreatment, e.g., heating with $\mathrm{HNO}_{3}$ and distillation, might improve the stability of the subsequent product, but the practicality of such treatment would necessarily depend upon the relative amounts of stable and unstable components.

Stability of Commercia1 Diisopropylbenzenes. A commercially available dilsopropylbenzene (66\% meta, $34 \%$ para, $\$ 0.5 \%$ ortho) was among the 
TABLE 6. STABILITY OF ALKYLBENZENES MADE FROM

$c_{9}$ TO $c_{24} \alpha$-OLEFINS ${ }^{a}$

\begin{tabular}{ccc}
\hline \multicolumn{1}{c}{ Alkylbenzene } & $\begin{array}{c}{ }^{181} \mathrm{Hf} \\
\text { Distribution } \\
\text { Coefficient } \\
\text { (Calcium Test) }\end{array}$ & $\begin{array}{c}\text { Organic-Phase } \\
\text { Nitrogen } \\
\text { Uptake } \\
(\underline{\mathrm{M}})\end{array}$ \\
\hline Detergent a 1kylate D-109 & 0.40 & 0.39 \\
Detergent a1kylate D-111 & 0.35 & 0.32 \\
Detergent alkylate D-110 & 0.26 & 0.34 \\
n-octy1 (pure) D-4 & 0.002 & 0.01 \\
\hline
\end{tabular}

${ }^{a_{1 M}}$ TBP Solutions in a lkylbenzene boiled under reflux for $4 \mathrm{hr}$ with an equal volume of $2 \mathrm{M} \mathrm{HNO}_{3}$.

${ }^{b}$ See "Experimental Methods." 
origina 1 diluents tested in 1962 (Table 1). Samples of meta- and paradifsopropyl benzenes have since been tested and GLC examinations, nitrogen analysis of the degraded materials, and DTA ( 5) confirm the instability which was indicated by the extraction tests. Boiling each of the isomers (IM TBP) with $2 \mathrm{M} \mathrm{HNO}_{3}$ for $4 \mathrm{hr}$ degraded them about 25\%, and the organic phases contained about 1 M nitrogen. GLC chromatograms showed only 1 major degradation product, and by analogy with DEB degradation, this product is expected to be:

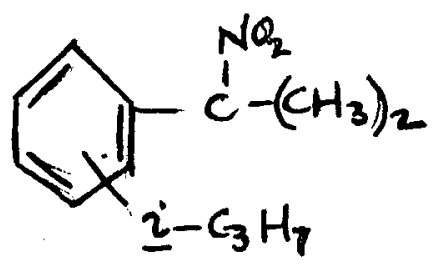

\section{SUMMARY OF ORNI DATA DESCRIBING STABILITIES OF SOME SELECTED SOLVENT EXTRACTION REAGENTS}

The preceding pages have described solvent degradation almost exclusively in terms of the diluent portion of the organic phase even though TBP was present during many of the degradations. TBP, however, has high stability in the area of its current application and its principle degradation products, when formed, are usually removed by simple alkaline scrubbing. The stabilities of some of the newer reagents which have been proposed for use are not so well known, however, and the following section constitutes a brief summary of the data which have been accumulated at ORNL pertaining to some of these reagents and gives reference to publications where the data are treated in more detail. 
It is interesting that while there is variety in the functional groups contained in these reagents, e.g., amine, pheno1, amide, the points of attack by acids are frequently at carbon atoms whose hydrogens are activated. In this respect the stabilities of both reagent and diluent against degradation by $\mathrm{HNO}_{3}$ and $\mathrm{HCl}$ are very much related.

Stability of Di-sec-butyl Phenylphosphonate. Undiluted di-secbutyl phenylphosphonate (DSBPP), a solvent extraction reagent with good hydrolytic stability and excellent ability to separate uranium from thorium, ${ }^{1}$ was irradiated $\left({ }^{60} \mathrm{Co}\right.$ gamma-ray source) to $100 \mathrm{whr} / 1$ iter while being stirred with $2 \mathrm{M} \mathrm{HNO}_{3}$. The fission product extraction power of the irradiated material was less than that of irradiated tributyl phosphate in a comparable test. Each reagent was nitrated to the extent of about 0.05 mole of nitrogen per mole of reagent. It was interesting to find that about one-third the nitrogen was removed from both reagents. by scrubbing with strong alkalies (e.g., IM LiOH) and at the same time the fission product extraction abilities were reduced to very low levels. The degree of reagent nitration noted in these tests was not predicted from previous tests ${ }^{9}$ in which the reagent had been irradiated with a 1imited amount of nitric acid dissolved in the organic phase and further tests are required to explain these results.

In further studies, solutions of TBP or DSBPP (each 1M) in DEB were irradiated to $70 \mathrm{whr} / 1$ while being stirred with $2 \underline{\mathrm{M}} \mathrm{HNO}_{3}$. Nitrogen uptake in the organic phases was $0.1 \underline{M}$ and $0.07 \underline{M}$, respectively, (Table 7) and GLC analyses indicated that the nitrogen was present almost completely in DEB-nitro compounds of Type 5. Extraction of ${ }^{181} \mathrm{Hf}$ from 
TABLE 7. COMPARISON OF HAFNIUM EXTRACTIONS BY DEGRADED DI-Sec-BUTYL PHENYLPHOSPHONATE (DSBPP) AND TBP

\begin{tabular}{|c|c|c|c|c|}
\hline \multirow{3}{*}{$\begin{array}{l}\text { Degraded } \\
\text { Solution }\end{array}$} & \multirow{3}{*}{$\begin{array}{l}\text { Nitrogen } \\
\text { Uptake } \\
\underline{M}\end{array}$} & \multicolumn{3}{|c|}{ Hafnium Extraction from $2 \underline{M} \mathrm{HNO}_{3}$ with } \\
\hline & & \multirow{2}{*}{$\begin{array}{l}{ }^{181} \mathrm{Hf} \text { Tracer } \\
\text { Distribution } \\
\text { Coefficient } \\
\text { (calcium test) }^{\mathrm{b}}\end{array}$} & \multicolumn{2}{|c|}{$\begin{array}{c}0.1 \mathrm{M} H \mathrm{Hf}_{3} \text { Moles } \\
\text { Complexed/1 Organic } \\
\text { Phase After }\end{array}$} \\
\hline & & & $\begin{array}{r}\mathrm{Na}_{2} \mathrm{CO}_{3} \\
\text { Scrub }\end{array}$ & $\begin{array}{l}\text { Calcium } \\
\text { Test }\end{array}$ \\
\hline $1 \underline{1} \underline{D S B P P} / \mathrm{DEB}$ & 0.07 & 1.4 & 0.0002 & 0.0006 \\
\hline IM TBP/DEB & 0.10 & 1.7 & 0.0002 & 0.0023 \\
\hline
\end{tabular}

a Irradiated while stirring with $2 \mathrm{M} \mathrm{HNO}_{3}$ In ${ }^{60} \mathrm{Co}$ source, 70 whr/1 exposure bee "Experimenta1 Methods" 
$2 \mathrm{M} \mathrm{HNO}_{3}$ (calcium test) was slightly lower with DSBPP solution than with that of $\operatorname{TBP}(D=1.4$ vs $D=1.7)$. Organic phase hafnium concentrations after

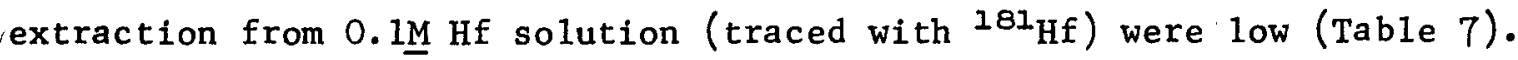

Phenyl substituted organophosphorus reagents have been reported lo to be susceptible to formation of phenol groups on the benzene ring ortho to the attached phosphorus atom, and it has been reported ${ }^{10}$ that the products extract fission products strongly. However, this is contradicted by IR and tracer studies. Infrared absorption by the irradiated $100 \%$ DSBPP in the 3200 wave number region attributable to phenol groups of this type was negligible in a method where the lower limit of analysis is 1 part in 250. A similar examination of the irradiated $1 \underline{M}$. DSBPP was made, but diluent absorption was too strong to permit phenol detection. It is difficult to determine relative hafnium extractions by reagent and diluent degradation products, but the low extractions from the strong $0.1 \mathrm{M}$ hafnium solution indicate low concentrations of any materials which extract hafnium strongly.

Stability of Amides. Amides, particularly those of low molecular weight, are subject to hydrolysis in both acid and alkaline media. Two commercially available amides,

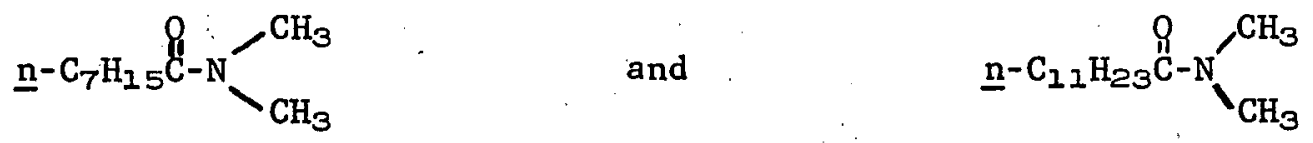
were each boiled (undiluted) with an equal volume of $2 \mathrm{M} \mathrm{HNO}_{3}$ under total reflux for $4 \mathrm{hr}$. The degraded amides were diluted to $1 \mathrm{M}$ (based on composition of the original sample) with DEB. These solutions were scrubbed several times with water and once with $0.2 \mathrm{M} \mathrm{Na} \mathrm{CO}_{3}$ to remove 
nitric acid. The scrubbed solutions were titrated with sodium hydroxide and were used to extract uranium and thorium from $2 \mathrm{M} \mathrm{HNO}_{3}$ ( $\mathrm{Table} 8$ ). The decrease in uranium distribution coefficient, $\operatorname{D\propto }[\text { amide }]^{2}$, indicated a decrease of amide concentrations by $40 \%$ and $30 \%$ respectively. The concentrations of carboxylic acid found (about $20 \%$ of initial amide) were in fair agreement with this, considering the probable loss of some carboxylic acid to the sodium carbonate scrub. In a similar test with TBP the uranium extraction coefficient indicated loss of $13 \%$ of the reagent. Sidda $11^{11}$ reports that other amides have greater stability against acidic hydrolysis than does TBP, e.g., compounds of the following structural type:<smiles>[R]C([R])C(=O)N(C)F</smiles>

Stability of Amines. An important application for amines is in the transuranium element (TRU) recovery program. In that program the Tramex process uses $0.6 \underline{M}$ tertiary amine hydrochloride (alamine 336-HC1) in DEB for TRU recovery from chloride solutions. Counter-current tests with ${ }^{242} \mathrm{Cm}$ at power densities varying from 5-10 watts/1 (reagent dose $\sim 5 \mathrm{whr} / 1)$ showed no adverse effect on solvent extraction due to $\alpha$ irradiation. 12

In nitrate systems, relatively high selectivity for plutonium nitrate over fission products in amine extraction, and high resistance of amines to radiation damage, have been noted ini general by various 
TABLE 8. STABILITY OF AMIDES

\begin{tabular}{|c|c|c|c|c|c|c|}
\hline \multirow[b]{2}{*}{ Ana 1ysis } & \multicolumn{2}{|c|}{$\begin{array}{c}\text { Dimethyl } \\
\text { n-octy1 amide }\end{array}$} & \multicolumn{2}{|c|}{$\begin{array}{c}\text { Dimethy } 1 \\
\text { n-dodecyl amide }\end{array}$} & \multicolumn{2}{|c|}{ TBP } \\
\hline & Initial & $\underline{\text { Degraded }}^{a}$ & Initial & $\underline{\text { Degraded }}^{a}$ & Initial & $\underline{\text { Degraded }}^{a}$ \\
\hline Titration (wt $\%$ acid) ${ }^{b}$ & 2 & 24 & 1 & 20 & - & - \\
\hline U Distribution Coefficient ${ }^{c}$ & 5 & 2 & 7 & 3 & 24 & 18 \\
\hline Th Distribution Coefficient ${ }^{c}$ & 0.1 & 0.02 & 0.11 & 0.04 & - & - \\
\hline \multicolumn{7}{|c|}{$\begin{array}{l}\text { andiluted amide or TBP boiled } 4 \mathrm{hr} \text { under reflux with an equa } 1 \text { volume of } 2 \mathrm{M} \mathrm{HNO}_{3} \text {. Degraded } \\
\text { diluted to } 1 \mathrm{M} \text { with fresh DEB. } 1 \mathrm{M} \text { Solution scrubbed with water and } 0.2 \mathrm{M} \mathrm{Na}_{2} \mathrm{CO}_{3} \cdot \\
\mathrm{b}^{-} \\
\text {Titration was with aqueous sodium hydroxide. Percent acid calculated as weight percent of } \\
\text { corresponding carboxylic acid. }\end{array}$} \\
\hline
\end{tabular}


laboratories. The following tests show that some zirconium-extracting material is produced on prolonged contact of the amine extractants with nitric acid. 13

A number of amines (Alamine 336 and trilaurylamines from severa1 sources) in fresh $0.3 \mathrm{M}$ solutions extracted from $\sim 10$ to as high as 200 $\mathrm{c} / \mathrm{sec} \mathrm{ml}$ from tracer solution at $\sim 10^{4} \mathrm{c} / \mathrm{sec} \mathrm{ml}$ in $2 \mathrm{M} \mathrm{HNO}_{3}$. Even the lowest of the corresponding apparent extraction coefficients, $\sim 10^{-3}$, is higher than the coefficient of $\sim 10^{-4}$ found in macro zirconium extraction. (This suggests that all the fresh amine solutions contained varyIng traces of zirconium-extracting impurities, although it is also possible that the tracer solution contained a higher proportion of extractable zirconium species than did the macro solutions, since the methods of preparation were not identical and zirconium behavior can be highly dependent on its history.) Simple acid and basic scrubs removed the extracted zirconium in rather sma 11 increments, e.g., usual1y 10 to $70 \%$ per scrub, corresponding to decontamination factors of only $\sim 3$ or less. The "Fresh TLA-Fresh Amsco" entry in Table 9 is typical. In contrast to the fairly low extraction by the fresh extractants, some amine solutions that had been used in a nitrate extraction system and then stored for approximately one year (containing extracted nitric acid) extracted up to $80 \%$ of the tracer activity from solutions at $\sim 10^{4} \mathrm{c} / \mathrm{sec} \mathrm{ml}$. Amine solutions $(0.3 \underline{M})$ treated with $10 \mathrm{M} \mathrm{HNO}_{3}$ for 2 days extracted $\sim 15-20 \%$ of the activity, and undiluted amines treated with $10 \mathrm{M} \mathrm{HNO}_{3}$ for $5-7$ days and then diluted to $0.3 \underline{M}$ extracted $\sim 3-5 \%$, or $300-500 \mathrm{c} / \mathrm{sec} \mathrm{ml}$. The extracted zirconium, like the smaller amounts extracted by fresh amine solutions, was removed only slowly by acid and basic scrubs. 
TABLE 9. Zr-Nb EXTRACTION BY FRESH AND DEGRADED EXTRACTANTS

$95 \mathrm{Zr}-\mathrm{Nb}$ head solution at $8922 \mathrm{c} / \mathrm{sec} \mathrm{ml}$, in $2 \mathrm{M} \mathrm{HNO}_{3}$

$0.3 \mathrm{M}$ Trilaurylamine nitrate $(86 \mathrm{~F})$ in Amsco $125-82 . \mathrm{A} / 0=1 / 1.5 \mathrm{~min}$ contact, Burrell shaker (Dash indicates step performed but activity not counted)

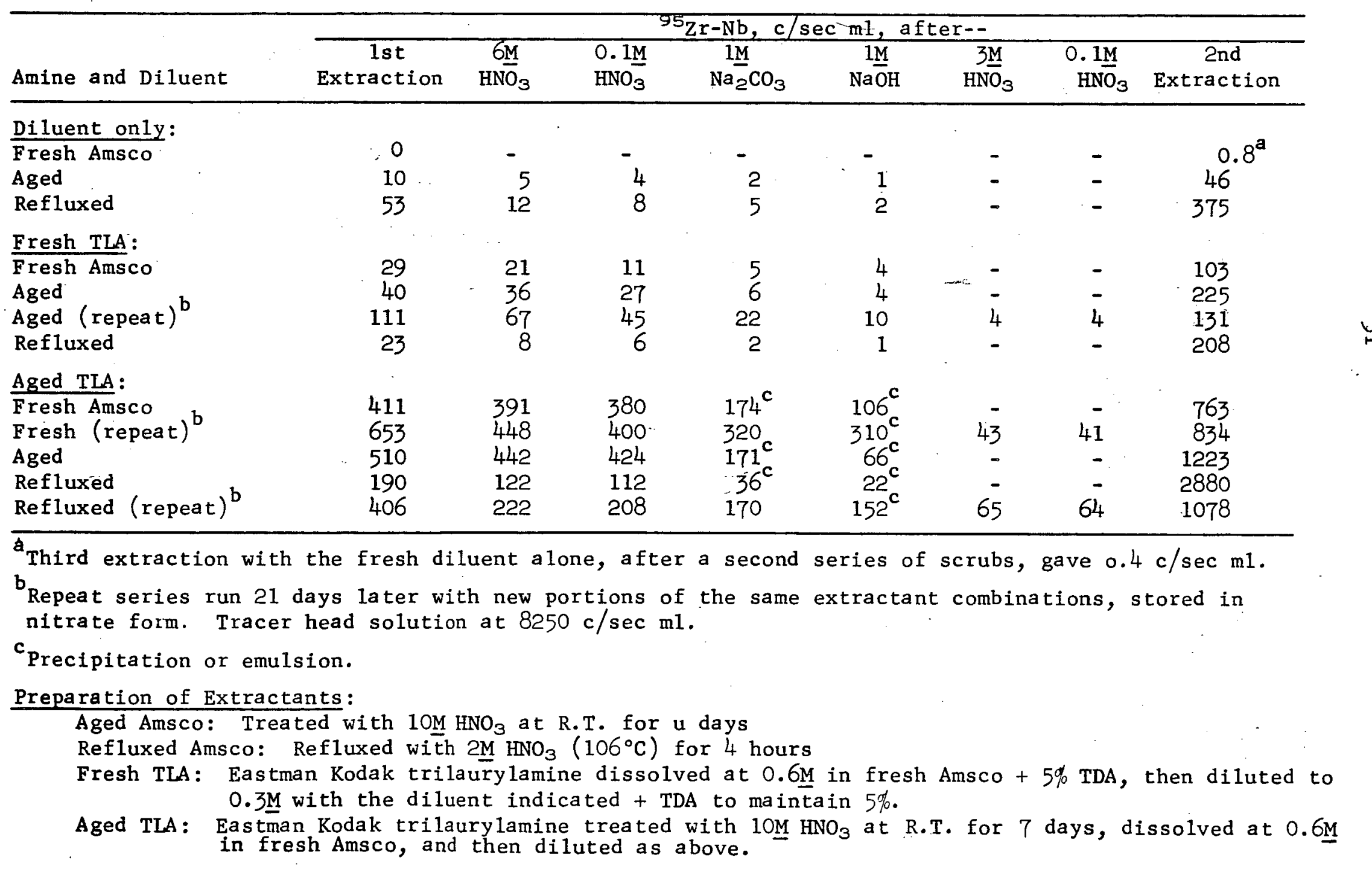


Fresh and degraded amines were dissolved in fresh and degraded diluents to compare zirconium extraction by the different combinations (Table 9). Each was equilibrated with $2-3 \underline{M} \mathrm{HNO}_{3}$ and then $0.1 \mathrm{M} \mathrm{HNO}_{3}$ before the zirconium extraction. Each extract was carried through a series of scrubs approximating the aqueous solutions it might encounter in process (cf Fig 4): (a) $6 \mathrm{M} \mathrm{HNO}_{3}$ (high-acid scrub), (b) $0.1 \mathrm{M}^{\mathrm{H}} \mathrm{HNO}_{3}$ (low-acid scrub and/or reductive or complexing stripping at low acidity, (c) $1 \underline{M} \mathrm{Na}_{2} \mathrm{CO}_{3}$ and (d) $1 \underline{M} \mathrm{NaOH}$ (basic solvent treatments), and (e) $2-3 \underline{M}$ $\mathrm{HNO}_{3}$ (recycle to raffinate stage of extraction). In each case the extractant was washed again with $0.1 \underline{M} \mathrm{HNO}_{3}$ to minimize possible effects of excess extracted acid on the tracer extraction. The major conclusions from Table 9 are that (1) Prolonged contact of $10 \mathrm{M} \mathrm{HNO}_{3}$ with the amine alone was much worse than with the diluent alone in producing zirconium-extracting material, and (2) The series of acid and basic scrubs increased the zirconium extraction power of each extractant. The latter suggest slow conversion of non-extracting to extracting forms, perhaps by oxidation, hydrolysis, tautomerism, etc.

In another study samples of five amines were irradiated to 200-400 watt $\mathrm{hr} / \mathrm{l}$ (no $\mathrm{HNO}_{3}$ present) at Stanford Research Institute (under subcontract to ORNL). Their samples and their unirradiated controls were compared with respect to titratable base content, and to extraction of uranium and fission products from nitric acid solution. ${ }^{14}$ Changes were smal1 in titratable base content ( $4-8 \%$ decrease), and in uranium distribution. There was little change in fission product extraction by two tertiary amines with straight a1kyls, but up to 10-fold increase in extraction by a tertiary, a secondary, and a primary amine, each with branched alkyls, suggesting that the hydrocarbon chains rather than the amines per se were involved. 
Stability of 4-sec-Buty1-2-( $\alpha$-Methylbenzy 1)Pheno1 (BAMBP). The substituted phenol, BAMBP, has utility in the recovery and separation of cesium and rubidium from the other alkali: metals by solvent extraction. ${ }^{15}$ BAMBP, however, when in contact with aqueous acidic nitrite solutions degrades severely with eventual loss of extraction power. The indications are that the degradation can be avoided by adding a sma11 amount of nitrite-destroying agent, such as sulfamic acid, to the aqueous solution.

Table 10 shows data for tests in which $1 \mathrm{M}$ BAMBP in Amsco 125-82 was contacted for several days at room temperature with various solutions and then subjected to a standard cesium extraction test. ${ }^{16}$ Treatment with $0.1 \mathrm{M} \mathrm{HNO}_{3}$ for 7 days had no apparent effect on the extraction properties of the solvent, but treatment with $0.1 \underline{M} \mathrm{NaNO}_{2}$ increased the extraction coefficient by a factor of 2-3. Spectrophotometric examination of the treated solvent showed an adsorption peak at $371 \mathrm{m \mu}$ which Hanford workers have found to be indicative of nitrated BAMBP. Extensive degradation occurred on contact with $0.1 \underline{M} \mathrm{HNO}_{3}-0.1 \mathrm{M} \mathrm{NaNO}_{2}$. After a few hours contact with this solution, the cesium extraction coefficient was 3-5 times higher than for untreated solvent, but extending the contact time to 4 days almost completely destroyed the extraction power. This effect was efficiently counteracted in another test, however, by adding sulfamic acid to the $0.1 \underline{M} \mathrm{HNO}_{3}-0.1 \underline{\mathrm{M}} \mathrm{HNO}_{2}$ solution to destroy the nitrite. With this procedure, extraction coefficients for solvent samples contacted for up to 9 days were the same as for untreated solvent and no indication of BAMBP nitration was found by spectrophotometric examination. 
TABLE 10. CHEMICAL STABILITY OF BAMBP

\begin{tabular}{|c|c|c|c|c|}
\hline \multicolumn{3}{|c|}{$\begin{array}{c}\text { Contacting Conditions } \\
\text { Aqueous Solution }\end{array}$} & \multirow{2}{*}{$\begin{array}{l}\text { Contact } \\
\text { Time } \\
\text { (days) }\end{array}$} & \multirow{2}{*}{$\begin{array}{l}\text { Cesium } \\
\text { Distribution } \\
\text { Coefficient }\end{array}$} \\
\hline $\mathrm{HNO}_{3}, \underline{\mathrm{M}}$ & $\mathrm{NaNO}_{2}, \underline{\mathrm{M}}$ & $\mathrm{NH}_{2} \mathrm{SO}_{3} \mathrm{H}, \underline{\mathrm{M}}$ & & \\
\hline , & No treatment & & & $4.2,4.8,4.9$ \\
\hline \multirow[t]{3}{*}{0.1} & & & 1 & 4.7 \\
\hline & $\gamma$ & & 3 & 4.7 \\
\hline & & & 7 & 5.4 \\
\hline \multirow[t]{3}{*}{0.1} & 0.01 & & 3 & 10.7 \\
\hline & & & 5 & 10.3 \\
\hline & & & $7^{\mathbf{b}}$ & 11.6 \\
\hline \multirow[t]{3}{*}{0.1} & 0.1 & & .0 .1 & 23 \\
\hline & & & 0.8 & 16 \\
\hline & & & $4^{b}$ & 0.09 \\
\hline \multirow[t]{4}{*}{0.1} & 0.1 & 0.2 & 0.2 & 5.1 \\
\hline & & & 1 & 5.6 \\
\hline & & & 5 & 4.3 \\
\hline & & & $9^{c}$ & 4.6 \\
\hline
\end{tabular}

Solvent treatment conditions: 1 M BAMBP in Amsco $125-82$ contacted at $25^{\circ} \mathrm{C}$ with aqueous solutions of composition shown. At each sampling time, the aqueous phase was replaced with fresh aqueous. Samples of the treated solvent were scrubbed with $1 \mathrm{M} \mathrm{NaNO}_{3}$ solutions; ( $\mathrm{pH} 12$ ) and subjected to standard cesium extraction tests.

Extraction at a phase ratio of $1 / 1$ from solution containing $3 \mathrm{M} \mathrm{NaNO}_{3}$, and $0.1 \mathrm{~g}$ of $\mathrm{Cs}$ per 1iter (and ${ }^{134} \mathrm{Cs}$ tracer) at $\mathrm{pH} 12$.

${ }^{b}$ spectrophotometric examination showed a strong absorption peak at 371 m.

${ }^{c}$ Spectrophotometric examination showed no absorption peak at $371 \mathrm{m \mu}$. 
An interesting, but as yet unexplained, ${ }^{17}$ increase in the cesium distribution coefficient occurs when the BAMBP/diluent phase remains in contact with an alkaline solution such as the Hanford Tank Farm Supernate $\left(8 \underline{\mathrm{M} \mathrm{Na}}{ }^{+}, 3 \underline{\mathrm{M}} \mathrm{NO}_{3}{ }^{-}, 3 \underline{\mathrm{M} \mathrm{CO}} \mathrm{CO}^{-2}, \mathrm{pH} 10.4\right)$. In this case the increase was gradua 1 and rose from an initial $D=4.7$ to $D=12.6$ in 7 days at room temperature. When the contact was with $2 \mathrm{M} \mathrm{NaOH}$, however, the coefficient increased by a factor of 2 in one day, but there was no further change for up to 14 days further contact. In either case there were no significant changes in the titratable phenol content of the solvent nor in its selectivity for cesium over metal contaminants. Phase separation properties were not impaired. No significant differences were discernible from IR or NMR spectra.

\section{ACKNOWLEDGMENTS}

The authors wish to acknowledge the assistance of W. E. Oxendine, who performed many of the experiments, and E. T. Solomons. We are particularly grateful to W. H. Baldwin of the ORNL Chemistry Division for advice and assistance. 


\section{REFERENCES}

1. Blake, C. A. Jr., Gresky, A. T., Schmitt, J. M., Mansfield, R. G., Comparison of Dialkyl Phenylphosphonates with TBP in Nitrate Systems, ORNL-3374, (Oak Ridge National Laboratory Jan. 8, 1963).

2.' Blake, C. A. Jr., Davis, W. Jr., Schmitt, J. M., Nuc1. Sc1. and Eng. 17, 626-637 (1963).

3. Blake, C. A. Jr., Ana1. Chem., 25, 1759 (1963).

4. Voswinke1, Berichte, 21, 2829 (1888); 222, 315 (1889).

5. Ast1e, M. J., Industrial Organic Nitrogen Compounds, p 91, ACS Monograph No. 150, (Reinhold, 1961).

6. Urbanski, T., Chemistry and Technology of Explosives, Vo1 1., (Pergamon Press, 1964).

7. Reed, R. L., Weber, L., Gottfried, B. S., Ind and Eng. Chem. Fund., 4, 38-46, (1965).

8. Carnes, W. J., Ana1. Chem., 36, 1197-1200 (1964).

9. Brown, K. B., Chemical Technology Division, Chemical Development Section C Monthly Progress Report, November 1959, ORNL-CF-59-11-132, (Oak Ridge Nationa 1 Laboratory Jan. 12, 1960).

10. Lane, E. S., Pilbeam, A., The Radiation Decomposition of Some Pheny1 Substituted Organo-Phosphorus (V) Extractant Systems, AERE-M-1284, (Atomic Energy Research Establishment, Harwel1 Jan. 1964).

11. Sidda11, T. H., III, Application of Amides as Extractants, DP-541, (Savannah River Laboratory Jan. 1961).

12. Leuze, R. E., Baybarz, R. D., Kappelmann, F. A., Weaver, B., Behavior of the Transplutonium Elements in Solvent Extraction Systems, (Paper to be published as part of this conference. Sixth session). 
13. Brown, K. B., Chemica1 Technology Division, Chemica1 Development

Section C Progress Report, February-March 1961, p 43, ORNL-CF-61-3-141, (Oak Ridge National Laboratory Aug. 15, 1961).

14. Horner, D. E., Coleman, C. F., Plutonium Extraction from Nitrate and

Sulfate Solutions by Amines and Organophosphorus Compounds, ORNL-3051, (Oak Ridge National Laboratory Feb. 23, 1961).

15. Arnold, W. D., Crouse, D. J., Brown, K. B., Ind. and Eng. Chem.,

Process Design and Dev., 4 , 249-254 (1965).

16. Chemica1 Technology Division, Annual Progress Report For Period Ending May 31, 1964, ORNL-3830 (Oak Ridge Nationa 1 Laboratory. To be issued November 1965).

17. Chemica1 Technology Division, Annual Progress Report For Period Ending May 31,1964, p 210, ORNL-3627, (Oak Ridge National Laboratory October 1964). 
Figure 1 CHROMATOGRAMS COMPARING DEGRADATION OF META-DIETHYLBENZENE (DEB) BY $2 \mathrm{M} \mathrm{HNO}_{3}$ IN THE PRESENCE AND IN THE ABSENCE OF ${ }^{60}$ Co IRRADIATION

Figure 2 DEGRADATION OF DIETHYLBENZENE (DEB) ISOMERS BY BOILING $2 \mathrm{M} \mathrm{HNO}_{3}$

(Percent DEB destroyed-by comparison of DEB GLC peak areas before and after degradation. Total degradation products growth in degradation product peak area with degradation)

Figure 3 DEGRADATION OF DIETHYLBENZENE (DEB) ISOMERS BY 2 M $\mathrm{HNO}_{3}$ IN THE PRESENCE OF ${ }^{60}$ Co IRRADIATION

(Percent DEB destroyed-by comparison of DEB GLC peak areas before and after degradation. Total degradation productsgrowth in degradation product peak area with degradation. Lines drawn from data of Fig 2.) 


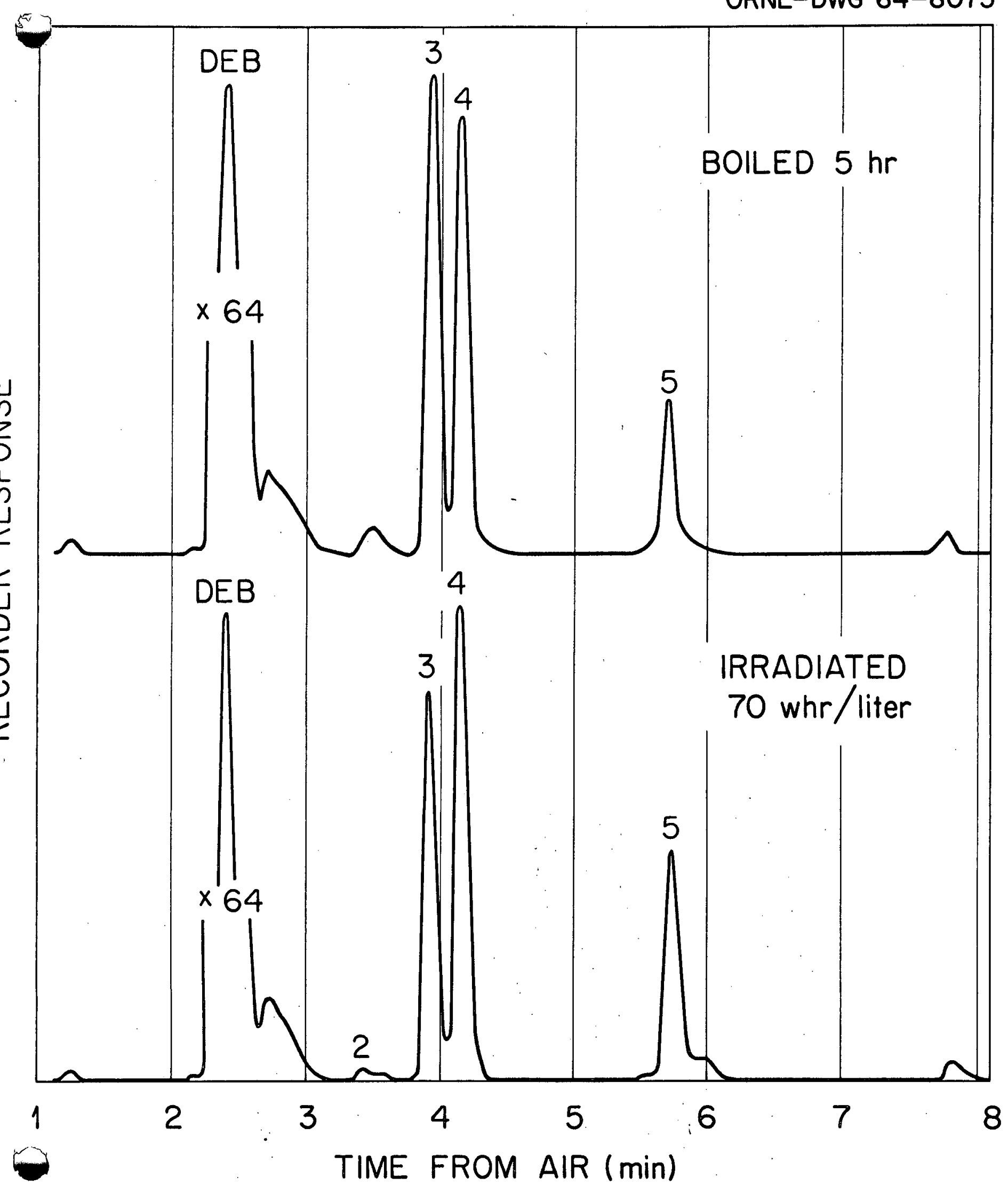




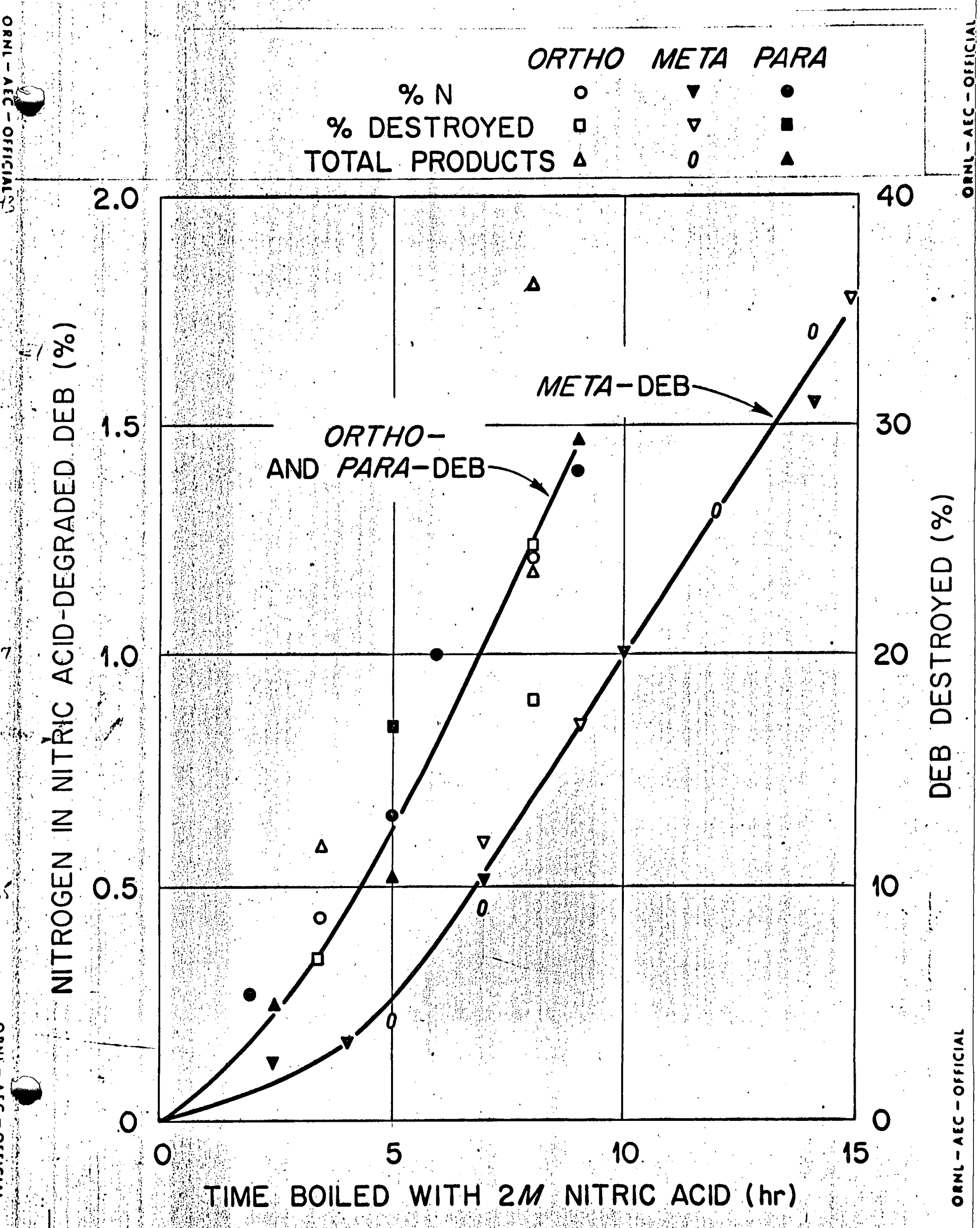




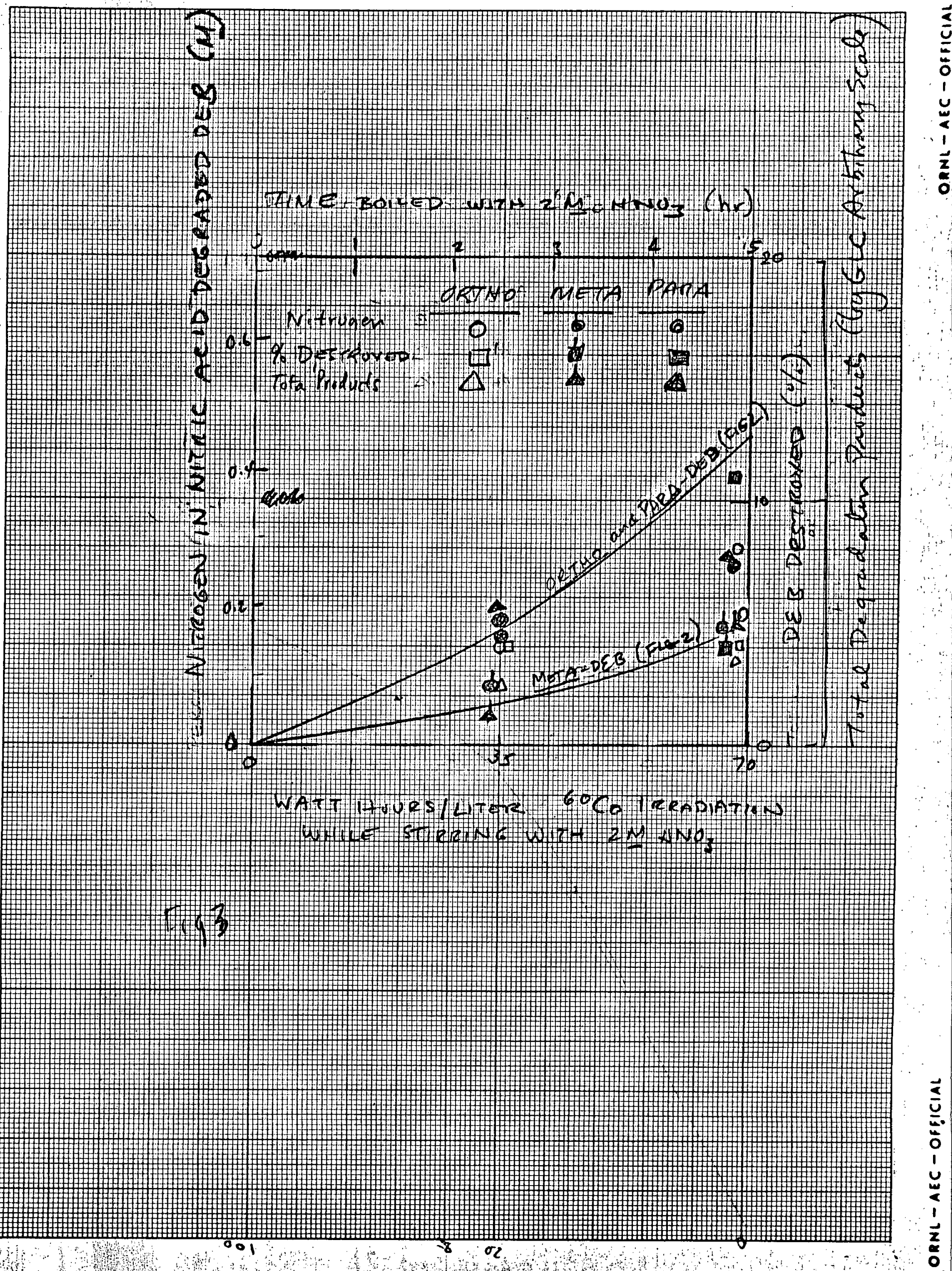

